\title{
Analysis of vertical, horizontal and deviated wellbores stability by analytical and numerical methods
}

\author{
Abbas Khaksar Manshad · H. Jalalifar • \\ M. Aslannejad
}

Received: 6 August 2013 / Accepted: 6 January 2014/Published online: 22 January 2014

(C) The Author(s) 2014. This article is published with open access at Springerlink.com

\begin{abstract}
Wellbore stability problems are known to cost the oil and gas industry billions of dollars each year. However, these costs can be significantly reduced through the application of comprehensive geomechanical models. This paper is relevant and is appropriate in the oil and gas industry. The objective of this paper is the comparison of four rock failure criteria, named the Mohr-Coulomb, MogiCoulomb, Modified Lade and Tresca yield criterion and to apply them to determine the optimum drilling direction and mud pressure. The stability models has been applied to a well located in Iran oil field and leads to easily computed expression for the critical mud pressure required to maintain wellbore stability. Then the finite difference method was used to show the validation and accuracy of predicted mud pressure and investigate the wellbore stability in different states of vertical, horizontal and deviated. The results showed that the Mohr-Coulomb and Tresca criteria estimate the highest minimum mud pressure required for wellbore stability while the Mogi-Coulomb and the Modified Lade criteria estimate the lowest minimum mud pressure. Nevertheless, the mud pressures predicted by all these four criteria are acceptable and can be used.
\end{abstract}

A. K. Manshad ( $₫)$

Department of Petroleum Engineering, Abadan Faculty of Petroleum Engineering, Petroleum University of Technology, Abadan, Iran

e-mail: Khaksar58@yahoo.com

H. Jalalifar

Department of Chemical and Petroleum Engineering,

Shahid Bahonar University, Kerman, Iran

M. Aslannejad

Department of Chemical and Petroleum Engineering,

Persian Gulf University, Boushehr, Iran
Keywords Wellbore stability - Failure criteria · Minimum mud pressure $\cdot$ Finite difference $\cdot$ Drilling

\section{Introduction}

Investigation of wellbore stability and advising a sensible plan before drilling require identification of problematic regions and improving of drilling operation. The two important elements needed in a wellbore stability model are the failure criterion and the constitutive behavior model. Wellbore drilling in a formation causes stress alteration around the borehole due to removal of rock. This stress alteration is important, since it leads to an increase in stress around the wall of the hole, therefore the induced stresses should be adjusted by choosing proper mud pressure to stabilize wellbore. Although the selection of an appropriate rock failure criterion for analyzing wellbore stability is difficult and controversial (Al-Ajmi and Zimmerman 2009; Mclean and Addis 1990), a number of rock failure criteria and behavior models have been accomplished for the diagnosis and prediction of wellbore instability. Since there is no single criterion suitable for all materials and situations, drilling engineers should be able to choose a suitable rock failure criterion based on formation rock properties to predict an optimum mud pressure to stabilize wellbore. Bradley (1979) was the first to model for compressive wellbore failure of a deviated well for the purpose of proposing proper mud weights to preclude borehole failure. However, he did all of his analyses for the rare case where the two horizontal stresses are equal and less than the vertical stress. Ewy (1999) found that the modified Lade criterion predicts critical mud weight values that are less conservative than those predicted by the Mohr-Coulomb criterion yet are not as unconservative as those predicted by the Drucker-Prager criterion. 
Al. Ajmi and Zimmerman (Al-Ajmi and Zimmerman 2004) introduced the fully polyaxial Mogi-Coulomb failure criterion, and then proposed a new 3D analytical model (2006) to approximate the mud weight needed to avoid failure for the vertical wells based on Mogi-Coulomb failure mechanism coupled with elastic theory. Their study shows the significant role of intermediate principle stress in rock strength, where using three dimensional Mogi-Coulomb failure criterion greater mud weight windows than Mohr-Coulomb failure mechanism have been obtained. Zhang et al. (2010) examined five failure criteria on various rock specimens to determine the best criterion for the wellbore stability analysis. Therefore, they concluded that the 3D Hoek-Brown and the Mogi-Coulomb criteria are appropriate for wellbore stability analysis.

On the other hand, numerical modeling methods provide an excellent opportunity to analyze the wellbore state of stress for different applications such as wellbore drilling, wellbore design or hydraulic fracturing (Lee et al. 2011). McLean and Addis (1994) used finite element methods to predict wellbore stability parameters. Chatterjee and $\mathrm{Mu}$ khopadhyay (2003) used ANSYS finite element software and investigated stress around a wellbore to study the effects of fluid pressure during drilling. Hoang et al. (2004) investigated wellbore stability in multilateral junctions using finite element method and showed that orientation of junction and in situ stresses both have significant impact on well completion and stability. Wang and Sterling (2007) performed numerical analyses named finite element to investigate the stability of a borehole wall during horizontal directional drilling in loose sand with an emphasis on the role of the filter cake in borehole stability. Muller et al. (2007) performed wellbore stability analysis with a finite element program that incorporates coupled fluidmechanical effects and elastoplastic behavior of the rock. Alberto et al. (Alberto and Sepehrnoori 2008) used commercial finite element software to investigate wellbore stability in multilateral open holes during drilling and production times and concluded that the most unstable region in multilaterals is the junctions (lateral wells). Salehi et al. (Salehi and Hareland 2010) investigated wellbore stability in underbalanced drilling with respect to equivalent circulating density with both Finite-Explicit and Finite-Element codes to cross-check the results.

In this paper, we will use first the Mohr-Coulomb, Mogi-Coulomb, Modified Lade and Tresca criteria to determine the optimum drilling direction and mud pressure for a well located in Iran oil field. Then the finite difference method is used to show the validation and accuracy of predicted mud pressure and investigate the wellbore stability in different states of vertical, horizontal and deviated.

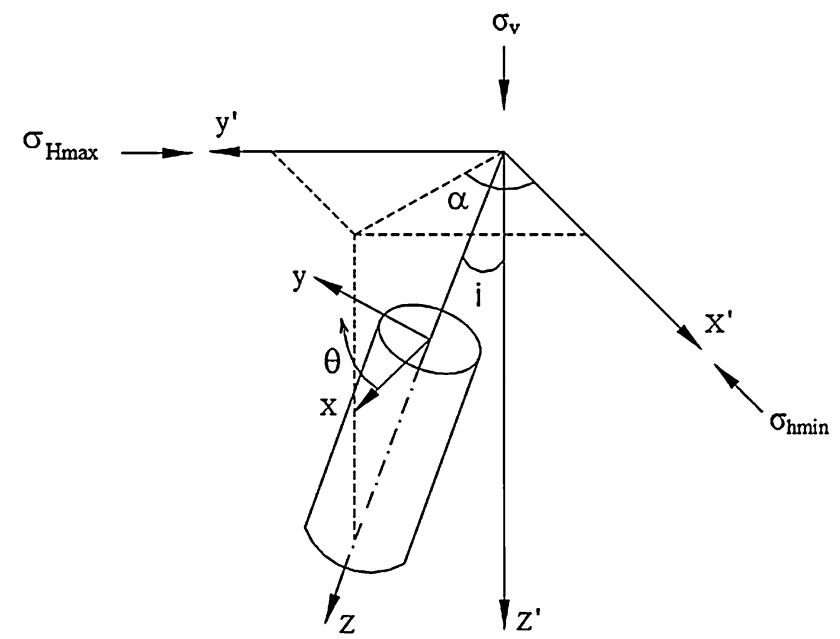

Fig. 1 Generalized stress transformation system for deviated borehole

\section{Stress distribution around the wellbore}

The in situ stresses of the virgin formation for a deviated well are given below in coordinate system.

$$
\begin{aligned}
\sigma_{\mathrm{x}}^{o} & =\left(\sigma_{\mathrm{H}} \cos ^{2} \alpha+\sigma_{\mathrm{h}} \sin ^{2} \alpha\right) \cos ^{2} i+\sigma_{\mathrm{v}} \sin ^{2} i, \\
\sigma_{\mathrm{y}}^{o} & =\left(\sigma_{\mathrm{H}} \sin ^{2} \alpha+\sigma_{\mathrm{h}} \cos ^{2} \alpha\right), \\
\sigma_{\mathrm{z}}^{o} & =\left(\sigma_{\mathrm{H}} \cos ^{2} \alpha+\sigma_{\mathrm{h}} \sin ^{2} \alpha\right) \sin ^{2} i+\sigma_{\mathrm{v}} \cos ^{2} i, \\
\sigma_{\mathrm{xy}}^{o} & =0.5\left(\sigma_{\mathrm{h}}-\sigma_{\mathrm{H}}\right) \sin 2 \alpha \cos i, \\
\sigma_{\mathrm{yz}}^{o} & =0.5\left(\sigma_{\mathrm{h}}-\sigma_{\mathrm{H}}\right) \sin 2 \alpha \sin i, \\
\sigma_{\mathrm{xz}}^{o} & =0.5\left(\sigma_{\mathrm{H}} \cos ^{2} \alpha+\sigma_{\mathrm{h}} \sin ^{2} \alpha-\sigma_{\mathrm{v}}\right) \sin 2 i .
\end{aligned}
$$

where $\sigma_{\mathrm{v}}, \sigma_{\mathrm{H}}$ and $\sigma_{\mathrm{h}}$ are the vertical, maximum and minimum horizontal stresses, respectively. The angle $\alpha$ correspond to the deviation of the borehole from $\sigma_{2}$, and the angle, $i$, represents the deviation of the borehole from $\sigma_{1}$ (see Fig. 1) (Aminul 2009).

Stresses around a vertical well

For a vertical well drilled in a homogeneous and isotropic elastic rock in which one principal stress (the overburden stress, $S_{\mathrm{v}}$ ) is parallel to the wellbore axis and $r=\alpha=0$, the effective stress at the wall of a vertical borehole is given by Al-Ajmi and Zimmerman (2006)

$$
\begin{aligned}
& \sigma_{\mathrm{rr}}=P_{\mathrm{w}}, \\
& \sigma_{\theta \theta}=\sigma_{\mathrm{H}}+\sigma_{\mathrm{h}}-2\left(\sigma_{\mathrm{H}}-\sigma_{\mathrm{h}}\right) \cos 2 \theta-P_{\mathrm{w}}, \\
& \sigma_{\mathrm{zz}}=\sigma_{E}-2 v\left(\sigma_{\mathrm{H}}-\sigma_{\mathrm{h}}\right) \cos 2 \theta,
\end{aligned}
$$

where $\sigma_{\theta \theta}$ is the tangential stress, $\sigma_{\mathrm{rr}}$ is radial stress, $\sigma_{\mathrm{zz}}$ is axial stress. 
Non-vertical borehole stress analysis

When analyzing stress and pore pressure distributions in and around wellbores the polar coordinate system is generally adopted. For the generalized plane strain formulation the stresses in polar coordinates are related to the cartesian coordinate stresses according to the following rules:

$$
\begin{aligned}
\sigma_{\mathrm{rr}} & =\sigma_{\mathrm{x}}^{o} \cos ^{2} \theta+\sigma_{\mathrm{y}}^{o} \sin ^{2} \theta+2 \sigma_{\mathrm{xy}}^{o} \sin \theta \cos \theta, \\
\sigma_{\theta \theta} & =\sigma_{\mathrm{x}}^{o} \sin ^{2} \theta+\sigma_{\mathrm{y}}^{o} \cos ^{2} \theta-2 \sigma_{\mathrm{xy}}^{o} \sin \theta \cos \theta, \\
\sigma_{\mathrm{zz}} & =\sigma_{\mathrm{z}}^{o}-v\left(2\left(\sigma_{\mathrm{x}}^{o}-\sigma_{\mathrm{y}}^{o}\right) \cos 2 \theta+4 \sigma_{\mathrm{xy}}^{o} \sin 2 \theta\right), \\
\sigma_{\theta \mathrm{z}} & =\sigma_{\mathrm{yz}}^{o} \cos \theta-\sigma_{\mathrm{xz}}^{o} \sin \theta \\
\sigma_{\mathrm{r} \theta} & =\left(\sigma_{\mathrm{y}}^{o}-\sigma_{\mathrm{x}}^{o}\right) \sin \theta \cos \theta+\sigma_{\mathrm{xy}}^{o}\left(\cos ^{2} \theta-\sin ^{2} \theta\right), \\
\sigma_{\mathrm{rz}} & =\sigma_{\mathrm{xz}}^{o} \cos \theta+\sigma_{\mathrm{yz}}^{o} \sin \theta,
\end{aligned}
$$

where $\theta$ is the angle with reference to the center of the wellbore in the polar coordinate system. The principal effective stresses in the local borehole coordinate system in which shear stress is zero are given by

$$
\begin{aligned}
& \sigma_{t \max }=\frac{1}{2}\left(\sigma_{\mathrm{zz}}+\sigma_{\theta \theta}+\sqrt{\left(\sigma_{\mathrm{zz}}-\sigma_{\theta \theta}\right)^{2}+4 \sigma_{\theta \mathrm{z}}^{2}}\right), \\
& \sigma_{t \min }=\frac{1}{2}\left(\sigma_{\mathrm{zz}}+\sigma_{\theta \theta}-\sqrt{\left(\sigma_{\mathrm{zz}}-\sigma_{\theta \theta}\right)^{2}+4 \sigma_{\theta \mathrm{z}}^{2}}\right) .
\end{aligned}
$$

where $\sigma_{\text {tmax }}$ is the largest and $\sigma_{\text {tmin }}$ is the smallest principal stress (Zoback 2007). Eventually, the calculated principal stresses can be used in rock failure criteria to assess wellbore stability.

\section{Rock failure criteria}

\section{Mohr-Coulomb criterion}

The Mohr-Coulomb shear-failure model is one of the most widely used models for evaluating borehole collapse due to its simplicity (Horsrud 2001; Fjaer et al. 2008). MohrCoulomb criterion can be expressed based on shear stress and the effective normal stress like below

$\tau=c+\sigma_{\mathrm{n}} \tan \phi$

where $\tau$ is the shear stress, $\sigma_{\mathrm{n}}$ is the normal stress, c and $\phi$ are the cohesion and the internal friction angles of the rock, respectively. The Mohr-Coulomb criterion uses unconfined compressive strength (UCS) and angle of internal friction $(\phi)$ to assess the failure, and then it can be expressed in terms of the maximum and minimum principal stresses, $\sigma_{1}$ and $\sigma_{3}$

$\sigma_{1}=\sigma_{\mathrm{c}}+q \sigma_{3}$

where $q$ is a parameter related to $\phi$ and $\sigma_{\mathrm{c}}$ is the unconfined compressive strength of the rock. The parameters $q$ and $\sigma_{\mathrm{c}}$ can be determined, respectively, by Zhang et al. (2010) $q=\tan ^{2}\left(45+\frac{\phi}{2}\right)=\frac{1+\sin \phi}{1-\sin \phi}$

$\sigma_{\mathrm{c}}=2 \mathrm{c} \tan \left(45+\frac{\phi}{2}\right)=\frac{2 \mathrm{c} \cos \phi}{1-\sin \phi}$.

This criterion can also be rewritten as follows:

$F=\left(\sigma_{\mathrm{c}}+q \sigma_{3}\right)-\sigma_{1}$.

Considering Mohr-Coulomb criterion, shear failure occurs if $F \leq 0$, and accordingly, the required mud weight to prevent failure in each mode of failure can be calculated.

\section{Mogi-Coulomb criterion}

The Mogi-Coulomb criterion was proposed by Al-Ajmi and Zimmerman (2004) and is simply written as

$\tau_{\text {oct }}=a+b \sigma_{\mathrm{m}, 2}$

where $\sigma_{\mathrm{m}, 2}$ and $\tau_{\mathrm{oct}}$ are the mean stress and the octahedral shear stress, respectively, that defined by

$\sigma_{m, 2}=\frac{\sigma_{1}+\sigma_{3}}{2}$

$\tau_{\mathrm{oct}}=\frac{1}{3} \sqrt{\left(\sigma_{1}-\sigma_{2}\right)^{2}+\left(\sigma_{2}-\sigma_{3}\right)^{2}+\left(\sigma_{3}-\sigma_{1}\right)^{2}}$

and $a$ and $b$ are material constants which are simply related to $\mathrm{c}$ and $\phi$ as follows

$a=\frac{2 \sqrt{2}}{3} c \cos \phi, b=\frac{2 \sqrt{2}}{3} \sin \phi$.

This criterion can also be rewritten as follow

$F=\left(a+b \sigma_{\mathrm{m}, 2}\right)-\tau_{\mathrm{oct}}$.

Considering Mogi-Coulomb criterion, shear failure occurs if $F \leq 0$.

Modified Lade criterion

Ewy (1999) proposed the modified Lade criterion by modifying the criterion of Lade and Duncan where only two rock strength parameters are required, cohesion and friction angle (Zoback 2007). The modified Lade criterion is given as

$\frac{\left(I_{1}^{\prime}\right)^{3}}{I_{3}^{\prime}}=27+\eta$,

where

$I_{1}^{\prime}=\left(\sigma_{1}+S\right)+\left(\sigma_{2}+S\right)+\left(\sigma_{3}+S\right)$

$I_{3}^{\prime}=\left(\sigma_{1}+S\right)\left(\sigma_{2}+S\right)\left(\sigma_{3}+S\right)$.

The parameters $S$ and $\eta$ are material constants that $S$ is related to the cohesion of the rock, while the parameter $\eta$ 
represents the internal friction. These parameters can be calculated directly from the Mohr-coulomb cohesion, $c$, and friction angle, $\varphi$, as follows:

$S=\frac{c}{\tan \phi}$

$\eta=\frac{4 \tan ^{2} \phi(9-7 \sin \phi)}{1-\sin \phi}$.

This criterion can be rewritten as follow

$F=27+\eta-\frac{\left(I_{1}^{\prime}\right)^{3}}{I_{3}^{\prime}}$.

According to this criterion failure occurs if $\mathrm{F} \leq 0$.

Tresca criterion or the maximum shear stress criterion

This yield criterion was proposed by Henri Eduard Tresca, who assumed that failure would occur if the maximum shear stress exerted on any plane inside the rock reaches some critical value, $\tau_{\max }$. In terms of the three principal stresses, this criterion would be written as

$\tau_{\max }=\frac{\sigma_{\max }-\sigma_{\min }}{2}$,

where $\sigma_{\max }$ and $\sigma_{\min }$ are the maximum and minimum principal stresses, respectively. Hence, the Tresca criterion is (Jaeger et al. 2007)

$\sigma_{1}=\sigma_{3}+2 \sigma_{c}$

This criterion can be rewritten as follow

$F=\sigma_{c}-\left(\sigma_{\max }-\sigma_{\min }\right)$

According to this criterion failure occurs if $F \leq 0$.

\section{Wellbore stability analysis by analytical method}

To predict the required mud pressure and the optimum well trajectory for preventing wellbore collapse, an extensive stress profile modeling is developed. To do this analysis, the integration of data (such as young's modulus, Poisson's ratio, pore pressure, etc.) from wireline logs and laboratory core analysis to calculate all necessary parameters are required to compute the shear failure criteria. This section discusses the models for rock failure. Rock failure is a complex process which is still not fully understood. To simplify the analysis further, it is assumed that rocks are homogeneous and isotropic and have a uniform wellbore pressure profile.

The workflow of the process developed in this paper to predict stability is provided in Fig. 2. These same calculations and workflow are used as a base to create the geomechanical model.
After understanding each step in the workflow process required to calculate the principal stresses, a Matlab geomechanical simulator was created to replicate this process and predict the required mud pressure and mud weight in different drilling path to prevent wellbore instability. The case study is conducted on a carbonate formation in Iran reservoir in which the well has vertically been drilled successfully with a mud density of $1.3 \mathrm{~g} / \mathrm{cm}^{3}$

The offset well data including the field stresses and rock properties are shown in Tables 1 and 2:

The mechanical properties of the rock were derived from open-hole logs and were calibrated with laboratory testing results after which a wellbore stability analysis was done, to predict the stresses around the wellbore area. Finally, a failure analysis was done base on the MohrCoulomb, the Mogi-Coulomb, the Modified-Lade, and the Tresca criteria to analyze boreholes with various inclinations and azimuths. It should be pointed out that the term overbalance pressure will be referred to the difference between mud pressure and pore pressure in this paper.

\section{Vertical wellbores}

The minimum mud pressure predicted by the Mohr-Coulomb, the Mogi-Coulomb, the Modified-Lade, and the Tresca criteria accompanying mechanical/stress properties is shown in Fig. 3. The Tresca criterion predicts higher minimum mud pressure than that predicted by the other three criteria, so it is considered more conservative. The predicted minimum mud pressure by Modified Lade criterion is the lowest; however, the Mogi-Coulomb and Mohr-Coulomb are in the middle of these two criteria. As illustrated in Fig. 3, the distance between predicted minimum mud pressures by the Modified-Lade, the MogiCoulomb, the Mohr-Coulomb, and the Tresca criteria increases gradually with increasing drilling depth that are equal to $107.33,111.8,114.09$ and $143 \mathrm{MPa}$, respectively, at the depth of $8,000 \mathrm{~m}$.

Figure 4 illustrates the result of required mud weight for wellbore stability versus depth predicted by four aforementioned criteria. The mud weight also expands down gradually with the increase in depth. The predicted mud weight by the Modified-Lade, the Mogi-Coulomb, the Mohr-Coulomb, and the Tresca criteria at the depth of $8,000 \mathrm{~m}$ are equal to $1.14,1.19,1.21$, and $1.52 \mathrm{~g} / \mathrm{cm}^{3}$, respectively. Therefore, the Tresca criterion predicts high mud weight and in contrast, the Modified-Lade criterion predicts the lowest mud weight required for wellbore stability. The mud weight predicted by the Mohr-Coulomb and the Mogi-Coulomb are close to each other in depth of interest. 
Fig. 2 Flow chart for calculating shear and tensile failure

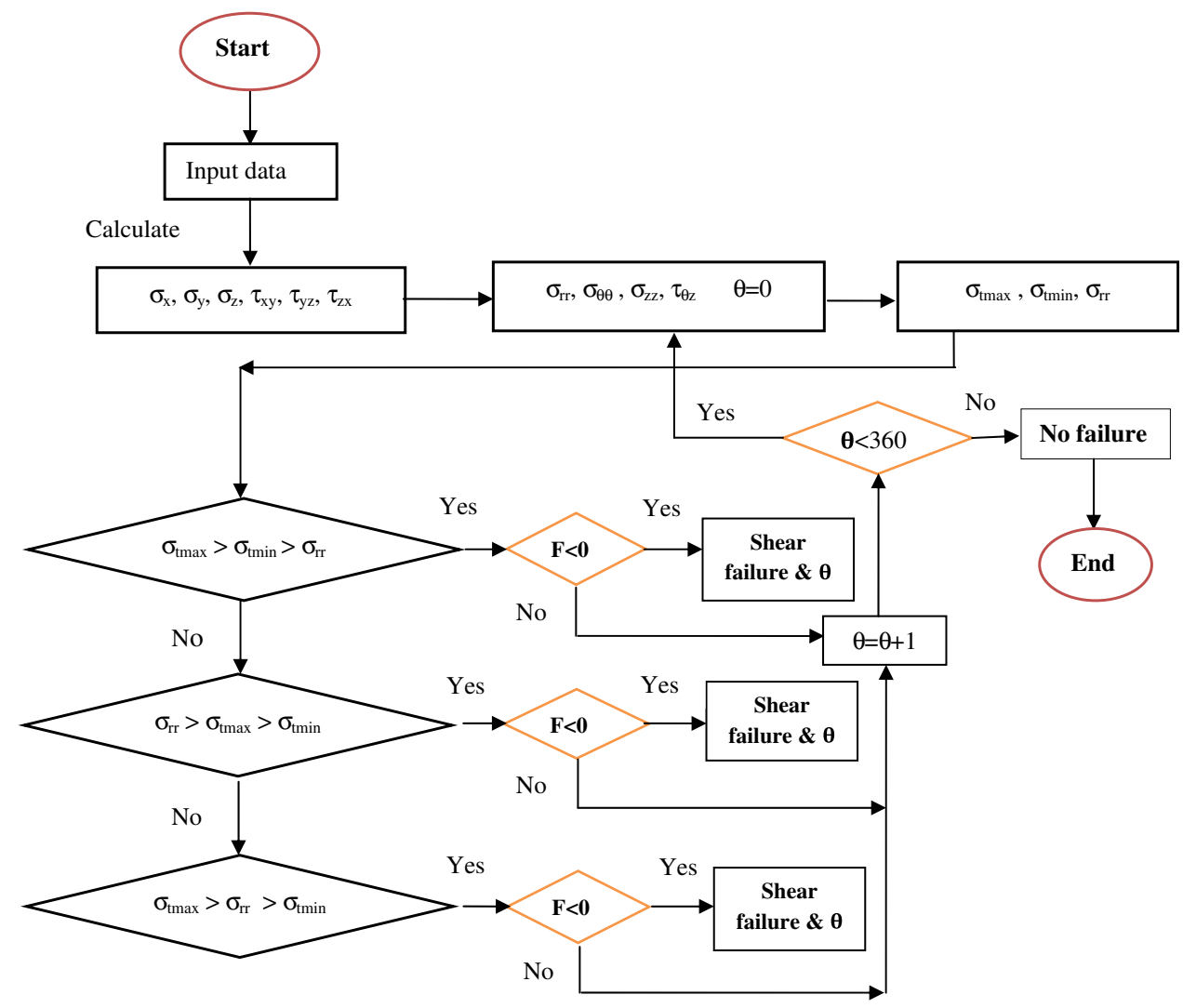

Table 1 In situ stress and pore pressure used in this study

\begin{tabular}{ll}
\hline Field stresses $(\mathrm{MPa})$ & values \\
\hline Overburden pressure $\left(\sigma_{\mathrm{v}}\right)$ & 80 \\
Maximum horizontal stress $\left(\sigma_{\mathrm{H}}\right)$ & 60 \\
Minimum horizontal stress $\left(\sigma_{\mathrm{h}}\right)$ & 58 \\
Pore pressure $(\mathrm{MPa})$ & 34.5 \\
Reservoir pressure $(\mathrm{MPa})$ & 40 \\
\hline
\end{tabular}

Table 2 Rock properties for a carbonate formation

\begin{tabular}{ll}
\hline Rock properties & Values \\
\hline Cohesion $(\mathrm{MPa})$ & 4 \\
Friction angle $\left(^{\circ}\right)$ & 40 \\
Poisson's ratio & 0.31 \\
\hline
\end{tabular}

\section{Deviated wellbores}

In deviated boreholes, the required mud pressure is affected by well azimuth and inclination. Figure 5 shows the minimum overbalance pressure for different drilling directions based on the Mohr-Coulomb, the Mogi-Coulomb, the Modified-Lade and the Tresca criteria. The results are for the rock at depth of 3,190 m. The lowest predicted overbalance pressure that is required to prevent borehole

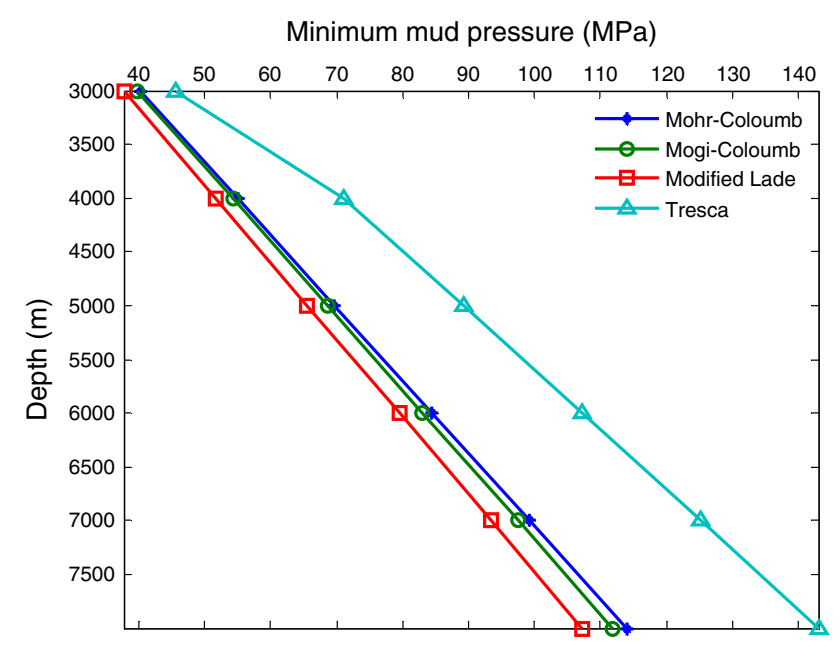

Fig. 3 Minimum mud pressure verses depth for a vertical borehole

instability is a $20^{\circ}$-deviated borehole in a direction parallel to the minimum in situ stress (i.e., $\sigma_{\mathrm{h}}$ ). The predicted minimum overbalance pressure by the Mohr-Coulomb criteria is higher than the Mogi-Coulomb and the Modified-Lade criteria and lower than the Tresca criterion.

Figure 5 also shows that the stability of the horizontal borehole $\left(i=90^{\circ}\right)$ is lower than the vertical one $\left(i=0^{\circ}\right)$; therefore it needs higher minimum overbalance pressure for being stable. The minimum overbalance pressure 


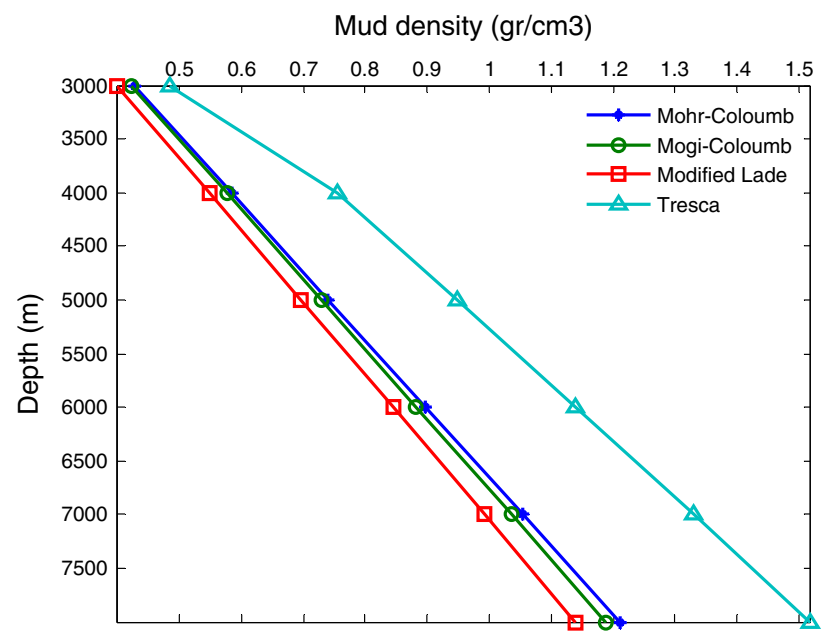

Fig. 4 Mud density verses depth for a vertical borehole

predicted by the Mohr-Coulomb criterion is $8.3 \mathrm{MPa}$, by the Mogi-Coulomb criterion is $8 \mathrm{MPa}$, by Modified Lade criterion is $6 \mathrm{MPa}$, and by the Tresca criterion is $16 \mathrm{MPa}$ in vertical state that is $6.5 \mathrm{MPa}$ more than actually used, which represents that the Tresca and Mohr-Coulomb criteria overestimate the minimum overbalance pressure. For Tresca criterion, in the inclination of more than $30^{\circ}$, the required minimum overbalance pressure for wellbore stability is approximately equal and merges together in different azimuths because of low difference between minimum and maximum horizontal stresses. It should be pointed out that increase in difference between minimum and maximum horizontal stresses causes these curves of various azimuths to move further away from each other. For inclined wellbores, the stress states around the wellbore altered and thus the required minimum overbalance pressures are affected by the wellbore orientation $(i, \alpha)$.

Figure 6 shows the variation of the minimum overbalance pressures in different wellbore inclination angle, $i$, for the borehole in carbonate, at orientation angles $\alpha=0^{\circ}, 30^{\circ}$, $60^{\circ}$ and $90^{\circ}$, respectively, based on different rock strength criteria. The Tresca criterion predicts the highest minimum overbalance pressures while the Modified-Lade criterion predicts the lowest minimum overbalance pressures. The modified Lade, Mogi-Coulomb criteria predict the minimum mud pressures that are close to each other and near the Mohr-Coulomb criterion.

For validation of the models, these criteria are applied on a well that has vertically been drilled successfully. Figure 7 shows the mud density as a function of wellbore inclination angle for the borehole at different orientation $\alpha$ at depth of $3,190 \mathrm{~m}$. The mud density predicted by the Tresca criterion is $1.35 \mathrm{~g} / \mathrm{cm}^{3}$ in vertical state that is $0.05 \mathrm{~g} / \mathrm{cm}^{3}$ more than actually used.

The reason for difference in the Mohr-Coulomb and the Tresca criteria with the Mogi-Coulomb and the Modified-
Lade criteria in determination of well trajectory, mud pressure, and mud weight is that, the Mohr-Coulomb and the Tresca criteria involve only the maximum and minimum principal stresses, $\sigma_{1}$ and $\sigma_{3}$, and therefore assume that the intermediate stress $\sigma_{2}$ has no influence on rock strength so the predicted rock strength is lower than the real one, and then it needs more mud pressure to be stable, and due to this fact, they are considered more conservative. Conversely, the Mogi-Coulomb and the Modified-Lade criteria consider intermediate stress $\sigma_{2}$ so they predict higher rock strength, and then the required mud weight for being stable is lower than that estimated by the MohrCoulomb and the Tresca criteria. Therefore, the MogiCoulomb and the Modified-Lade criteria represent field conditions more realistic than do the Mohr-Coulomb and the Tresca criteria.

\section{Validation of mud pressures predicted by four rock failure criteria via finite difference method}

In this part, validation of mud pressures predicted by Tresca, Mohr-Coulomb, Mogi-Coulomb, and ModifiedLade criteria is investigated. The finite difference method is used to simulate wellbore stability with predicted pressures to ensure the accuracy of the results.

Figure 8 shows displacement around the wellbore drilled with different mud pressures predicted by the four aforementioned rock failure criteria. The displacements around the vertical well have maximum value and reduce in parts far from the wellbore. The maximum and minimum displacements belong to Lade and Tresca criteria that are 0.052 and $0.027 \mathrm{~mm}$, respectively.

Figure 9 shows maximum principle stress around the vertical well. The maximum principle stresses caused by various mud pressures have utmost value in the vicinity of wellbore. The highest and the lowest maximum principle stresses belong to Lade and Tresca criteria that are 80 and $68 \mathrm{MPa}$, respectively. These induced stresses merge together at the distances far from the wellbore and finally reach in situ stress. It is noted that decrease in the number of mud pressure leads to an increase in maximum principle stress.

The minimum principle stress around the vertical well is illustrated in Fig. 10. The highest minimum principle stresses belong to Tresca criterion that is equal to $51 \mathrm{MPa}$. The minimum induced stresses caused by other criteria are nearly the same. These stresses are used to investigate the wellbore stability, for instance failure occurs provided that the value of these stresses exceeds rock strength. Therefore, monitoring the induced stresses in the vicinity of the well is absolutely essential that can be controlled by predicting a safe mud window and then prevents wellbore instability. 

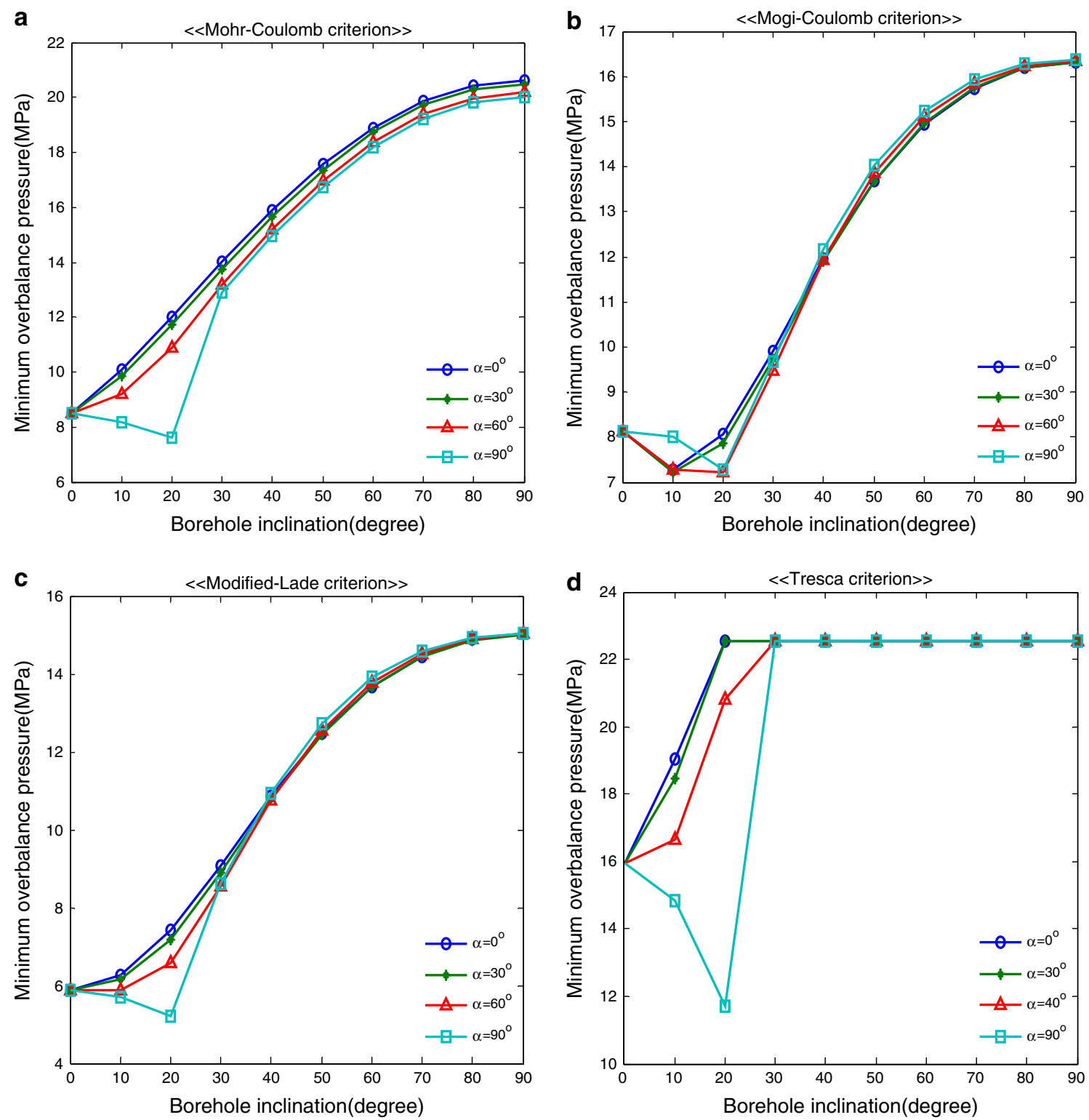

Fig. 5 Predicted mud pressure using the Mohr-Coulomb, the Mogi-Coulomb, the Modified-Lade, and the Tresca criterion

As depicted in Figs. 8, 9, 10, the displacements, maximum and minimum principle stresses around the well generated by the Mohr-Coulomb, Mogi-Coulomb, modified Lade criteria, and the actual drilling mud pressures are very close to each other since there is a little difference between the predicted pressures.

Figure 11 shows Mohr failure in shear-normal stress space that represents stability or instability of wellbore. Wellbore failure occurs provided that the maximum principal stress exceeds the effective strength (Mohr-Coulomb failure criterion is used here to account for the confining effect) and reaches Mohr failure envelope shown in Figure. Therefore, to stabilize wellbore, the stress state should always be lower than Mohr failure envelope. This Figure shows the stress state while drilling with mud pressure predicted by modified-Lade and since the stress state is lower than Mohr failure envelope, no failure occurs and the well is stable.

Figure 12 shows Mohr failure in principle stress space. This Figure also shows the stress state while drilling with mud pressure predicted by modified-Lade and since the stress state is lower than Mohr failure envelope, no failure occurs and the well is stable. The reason that we used modified-Lade mud pressure is that this pressure is lower than other predicted pressures and if this pressure shows stability then the other pressures also keep the well stable.

Eventually, the final results of validation of predicted mud pressures in vertical and horizontal wells are 

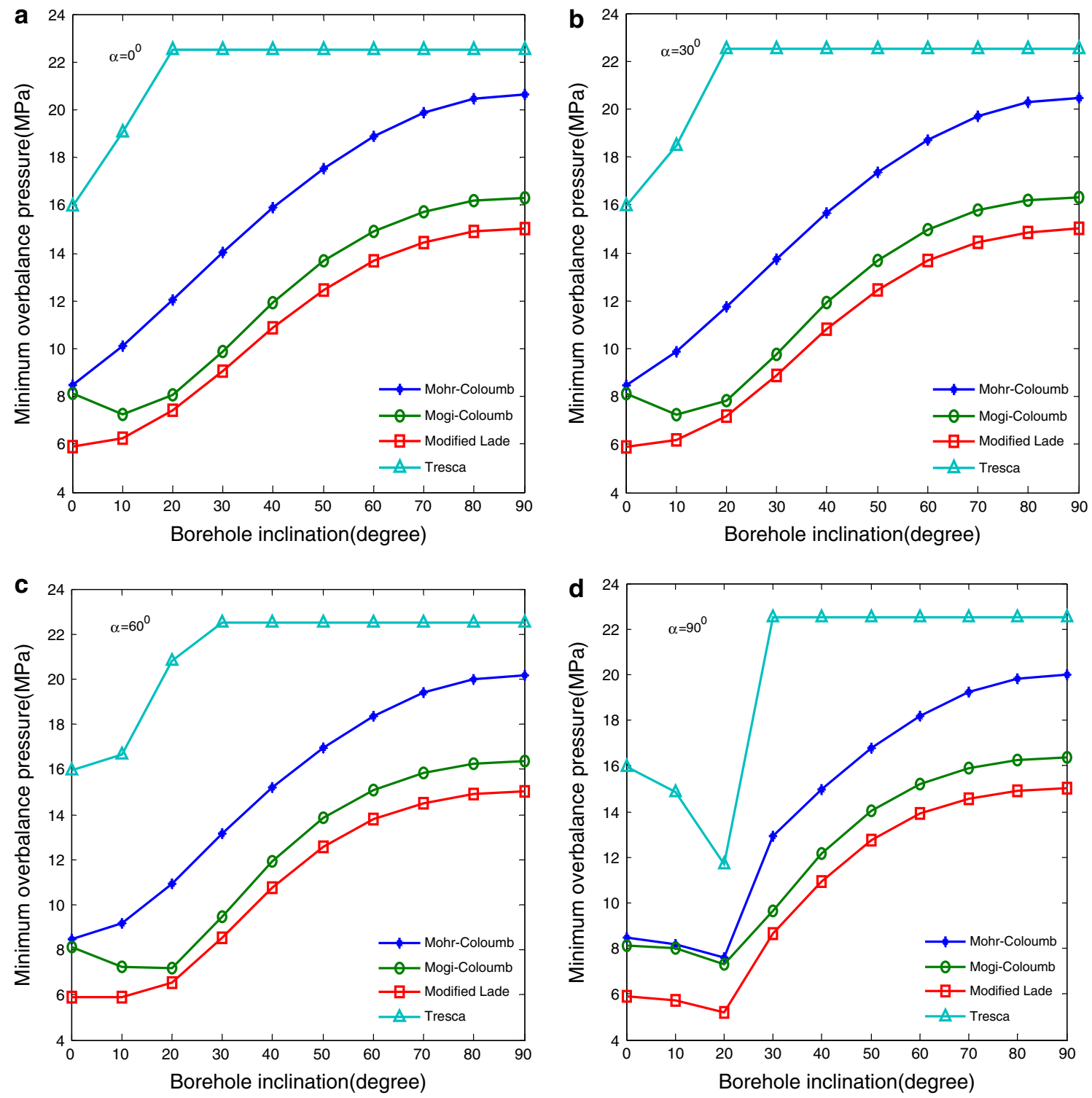

Fig. 6 Minimum overbalance pressure as a function of wellbore inclination angle for the borehole at different orientation $\alpha$

summarized and listed in Tables 3 and 4, respectively. Table 3 shows the maximum displacement, maximum and minimum principle stresses created by Tresca, MohrCoulomb, Mogi-Coulomb, and modified-Lade.

Table 4 shows the results of validation for horizontal well. The obtained results for horizontal drilling parallel to both maximum and minimum principle stress are nearly similar to each other.

Therefore, the mud pressures predicted by all these criteria are acceptable and can be used with exception of Tresca criterion, since it overestimates the required mud pressure for wellbore stability. Therefore, a mud pressure range of $40.38-43 \mathrm{MPa}$ is recommended for drilling the vertical section and 49.53-55.14 for horizontal sections of the mentioned well. This is $0.38-3 \mathrm{MPa}$ higher than reservoir pressure. This difference is enough to guarantee wellbore stability conditions.

\section{Conclusions}

Through this work, the following conclusions can be made:

The Tresca criterion accompanied by the Mohr-Coulomb, Mogi-Coulomb, and Modified Lade criteria was used to estimate minimum overbalance pressure and mud density in vertical and deviated wellbore. The method was demonstrated on a oil field case. The mud weight required to prevent breakout generation and maintain wellbore 

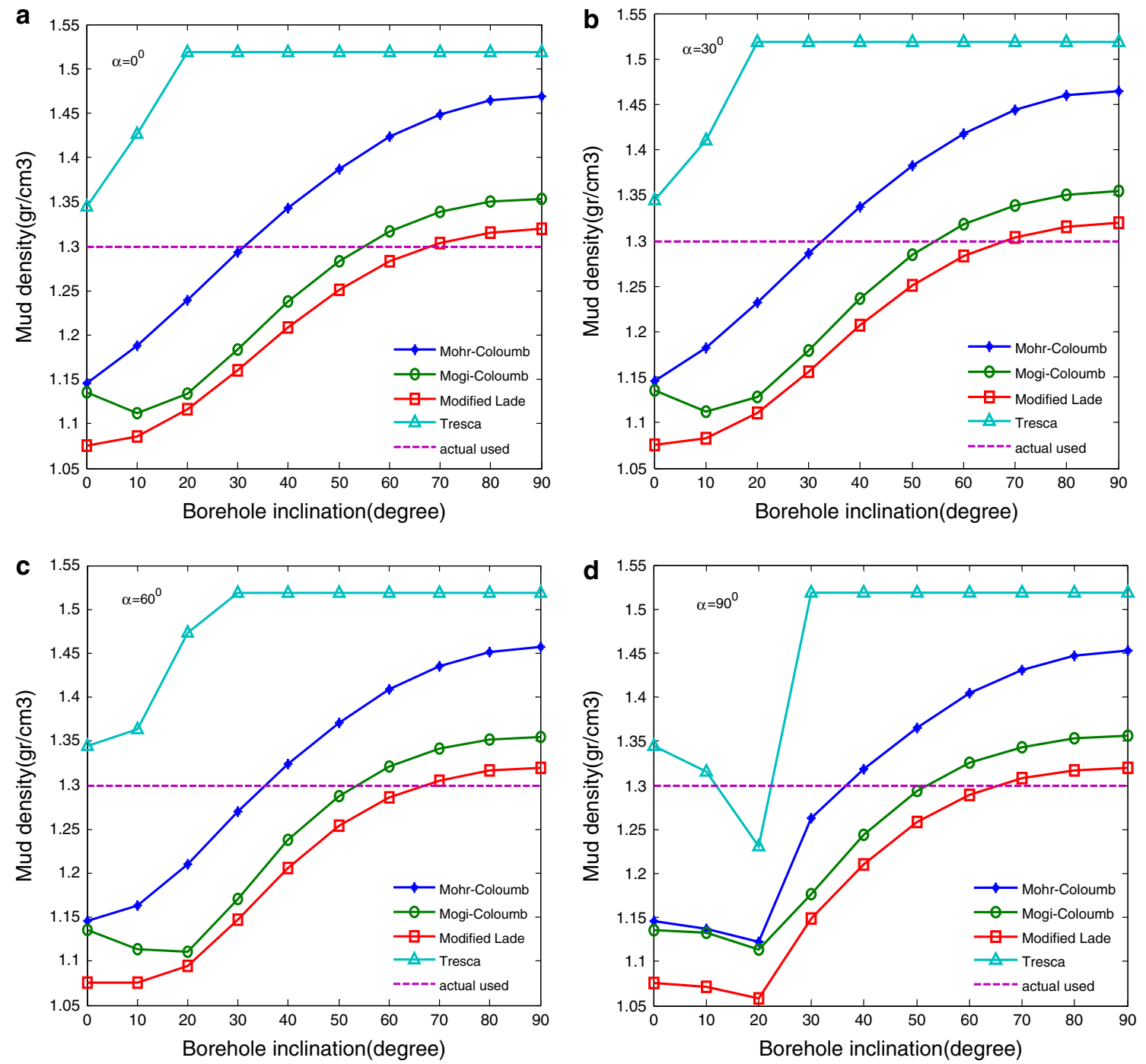

Fig. 7 Mud density as a function of wellbore inclination angle for the borehole at different orientation

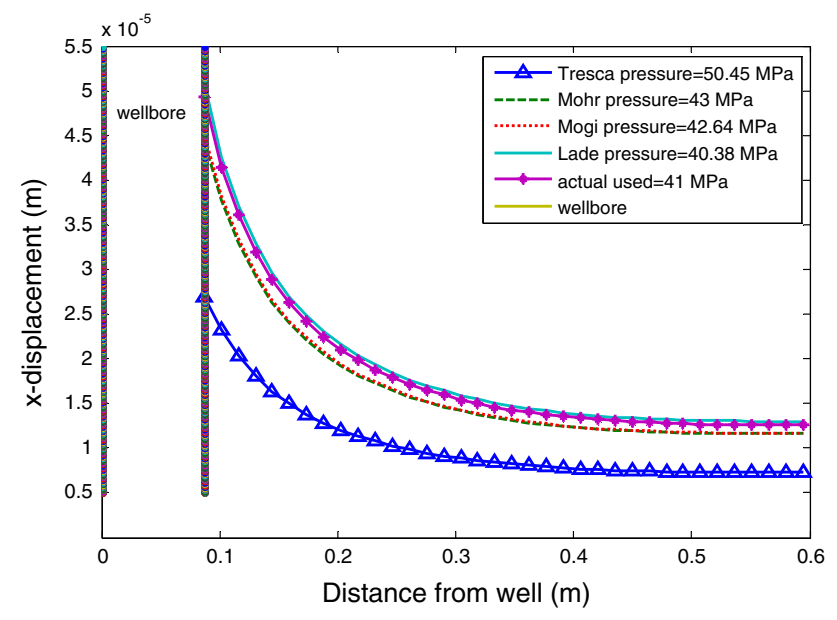

Fig. 8 Displacements around the vertical well drilled by predicted mud pressures

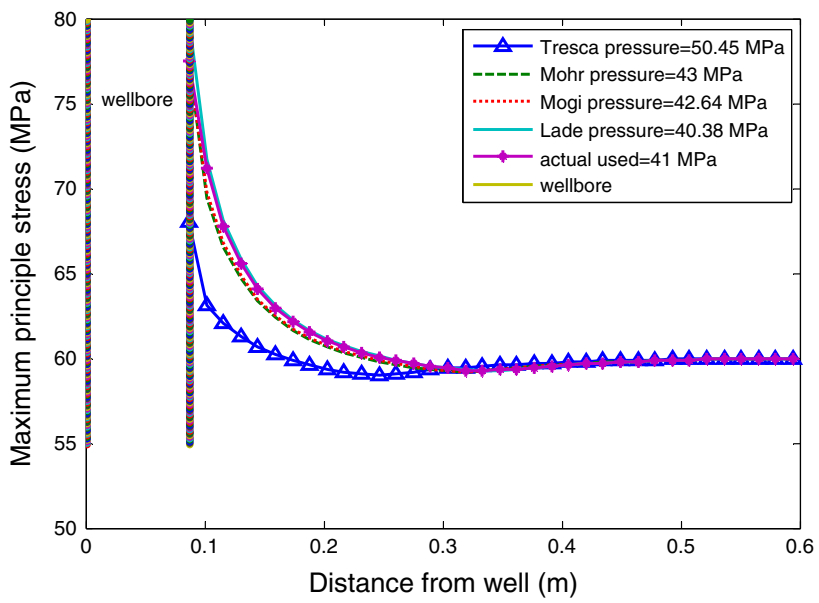

Fig. 9 Displacements around the vertical well drilled by predicted mud pressures 


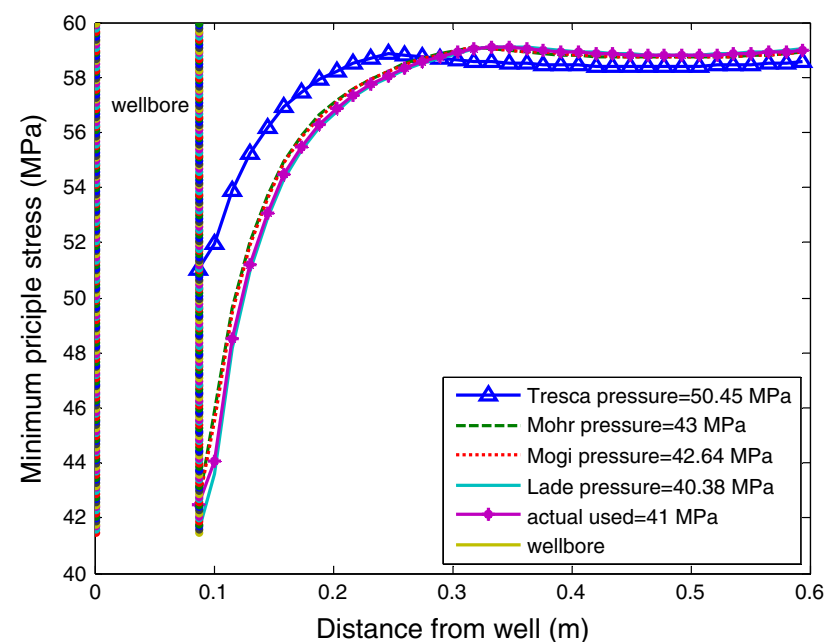

Fig. 10 Maximum principle stress around the vertical well drilled by predicted mud pressures

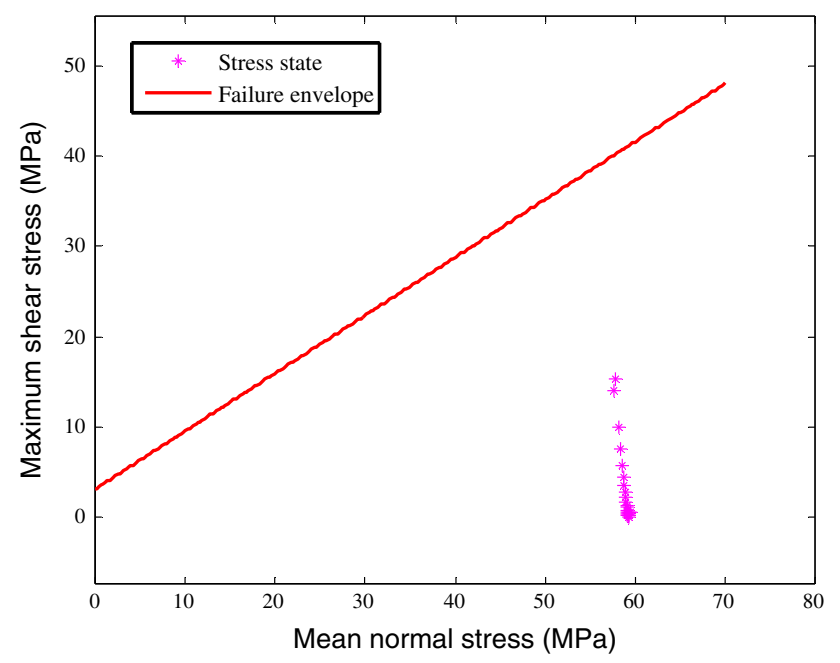

Fig. 11 Mohr failure in shear- normal stress space

stability during drilling was determined. At a wellbore inclination of $20^{\circ}$ the minimum mud density required for wellbore stability was found at azimuth $90^{\circ}$ that represents drilling in the minimum horizontal stress direction as the safest drilling direction. The estimated values by Tresca were relatively more than actual used, and overestimates the minimum mud pressure.

An elastoplastic model combined with both analytical and Finite-Difference codes was used for mechanical wellbore stability analysis of Iranian oil field. According to the results and compared with field data using elastoplastic models good predictions for wellbore stability in this field are given.

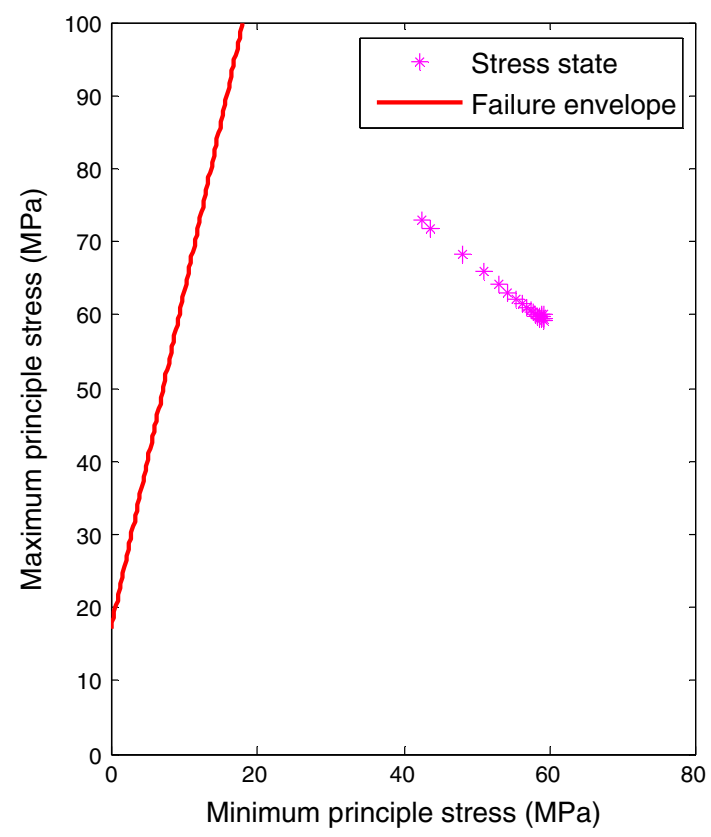

Fig. 12 Mohr failure in principle stress space

Table 3 Comparison of four rock failure criteria in vertical well

\begin{tabular}{lllll}
\hline $\begin{array}{l}\text { Rock } \\
\text { failure } \\
\text { criteria }\end{array}$ & $\begin{array}{l}\text { Predicted } \\
\text { mud } \\
\text { pressure } \\
(\mathrm{MPa})\end{array}$ & $\begin{array}{l}\text { Maximum } \\
\text { displacement } \\
(\mathrm{m})\end{array}$ & $\begin{array}{l}\text { Maximum } \\
\text { principle } \\
\text { stress (MPa) }\end{array}$ & $\begin{array}{l}\text { Minimum } \\
\text { principle } \\
\text { stress (MPa) }\end{array}$ \\
\hline $\begin{array}{l}\text { Tresca } \\
\text { Mohr- } \\
\text { Coulomb }\end{array}$ & 50.45 & $2.695 \times 10^{-5}$ & 68 & 51 \\
$\begin{array}{c}\text { Mogi- } \\
\text { Coulomb }\end{array}$ & 42.64 & $4.431 \times 10^{-5}$ & 77.5 & 42.5 \\
$\begin{array}{c}\text { Modified- } \\
\text { Lade }\end{array}$ & 40.38 & $5.154 \times 10^{-5}$ & 80 & 42.5 \\
\hline
\end{tabular}

Table 4 Comparison of four rock failure criteria in horizontal well

\begin{tabular}{lllll}
\hline $\begin{array}{l}\text { Rock } \\
\text { failure } \\
\text { criteria }\end{array}$ & $\begin{array}{l}\text { Predicted } \\
\text { mud } \\
\text { pressure } \\
(\mathrm{MPa})\end{array}$ & $\begin{array}{l}\text { Maximum } \\
\text { displacement } \\
(\mathrm{m})\end{array}$ & $\begin{array}{l}\text { Maximum } \\
\text { principle } \\
\text { stress (MPa) }\end{array}$ & $\begin{array}{l}\text { Minimum } \\
\text { principle } \\
\text { stress (MPa) }\end{array}$ \\
\hline $\begin{array}{l}\text { Tresca } \\
\text { Mohr- } \\
\text { Coulomb }\end{array}$ & 57.02 & $8.475 \times 10^{-4}$ & 110 & 42.5 \\
$\begin{array}{c}\text { Mogi- } \\
\text { Coulomb }\end{array}$ & 50.82 & $8.494 \times 10^{-4}$ & 110 & 45 \\
$\begin{array}{c}\text { Modified- } \\
\text { Lade }\end{array}$ & 49.53 & $8.555 \times 10^{-4}$ & 110 & 47.5 \\
\hline
\end{tabular}


Open Access This article is distributed under the terms of the Creative Commons Attribution License which permits any use, distribution, and reproduction in any medium, provided the original author(s) and the source are credited.

\section{References}

Al-Ajmi AM, Zimmerman RW (2004) Relation between the Mogi and the Coulomb failure criteria. Int J Rock Mech Min Sci 42:431-439

Al-Ajmi AM, Zimmerman RW (2006) Wellbore stability analysis based on a new true-triaxial failure criterion. Dissertation, University of KTH, Oklahoma

Al-Ajmi AM, Zimmerman RW (2009) A new well path optimization model for increased mechanical borehole stability. J Petrol Sci Eng 69:53-62

Alberto LM, Sepehrnoori K (2008) Modeling of the stability of multibranch horizontal open holes. SPE 114117:1-7

Aminul I (2009) Underbalanced Drilling in shales-perspective of mechanical borehole instability. International petroleum technology conference 13826

Bradley WB (1979) Failure of inclined boreholes. J Energy Res Technol 101:232-239

Chatterjee R, Mukhopadhyay M (2003) Numerical modelling of stress around a wellbore. SPE 80489:1-8

Ewy RT (1999) Wellbore stability predictions by use of a modified lade criterion. SPE Drilling \& Completion, pp 85-91

Fjaer E, Holt R, Horsrud P, Raaen A, Risnes R (2008) Petroleum related rock mechanics, 2nd edn. Elsevier, Amsterdam
Hoang S, Abousleiman Y, Tare U (2004) The analytical solution for wellbore stability in multilateral junctions in nonhydrostatic insitu stress field. SPE 90245:1-9

Horsrud P (2001) Estimating mechanical properties of shale from empirical correlations. SPE Drilling \& Completion, pp 68-73

Jaeger JC, Cook NGW, Zimmerman RW (2007) Fundamentals of rock mechanics. Blackwell, Oxford

Lee M, Eckert A, Nygaard R (2011) Mesh optimization for finite element models of wellbore stress analysis. 45th US rock mechanics/geomechanics symposium, San Francisco, California

McLean M, Addis M (1990) Wellbore stability: the effect of strength criteria on mud weight recommendations. Proceedings of the 65th SPE annual technical conference exhibition, New Orleans, paper SPE 20405

Mclean MR, Addis MA (1994) Wellbore stability analysis: a review of current methods of analysis and their field application. IADC/ SPE Drilling Conf, Houston, TX, pp 261-274

Muller AL, Euripedes AV, Luiz EV, Clemente JG (2007) Borehole stability analysis considering spatial variability and poroelastoplasticity. Int J Rock Mech Min Sci 46:1-7

Salehi S, Hareland GN (2010) Numerical simulation of wellbore stability in under-balanced-drilling wells. J Petrol Sci Eng 72:229-235

Wang X, Sterling RL (2007) Stability analysis of a borehole wall during horizontal directional drilling. Tunn Undergr Space Technol 22:620-632

Zhang L, Cao P, Radha KC (2010) Evaluation of rock strength criteria for wellbore stability analysis. Int J Rock Mech Min Sci 47:1304-1316

Zoback MD (2007) Reservoir geomechanics. Cambridge University Press, Cambridge 